\title{
The importance of private lands for ocelot Leopardus pardalis conservation in the United States
}

\author{
Aaron M. Haines, Jan E. Janecka, Michael E. Tewes, Lon I. Grassman Jr and Patricia Morton
}

\begin{abstract}
The distribution of ocelots Leopardus pardalis in the USA is limited to southern Texas. Identification and monitoring of ocelot populations enables biologists to assess population health and status. Use of camera traps has been successfully used to monitor numerous populations of wild felids, including the ocelot. Our objectives were to identify ocelot presence within southern Texas and estimate ocelot population size and density. We used camera traps to survey for ocelots on four study sites in southern Texas. We recorded ocelot
\end{abstract}

presence on one study site with an abundance estimate of three individuals and a density estimate of $0.30 \pm \mathrm{SE}$ 0.03 ocelots $\mathrm{km}^{-2}$. The conservation implications of this study suggest concentrating conservation efforts in and around the study site (Yturria Ranch) found to have ocelots. In addition, this study emphasizes the importance of including private landowners in the ocelot recovery process.

Keywords Camera trap, density, Endangered species, Leopardus pardalis, ocelot, survey, Texas.

\section{Introduction}

During the 1800s the range of ocelots Leopardus pardalis albescens in the USA included east and central Texas, western Louisiana and southern Arkansas (Woodward, 1980; Navarro-Lopez, 1985; Fig. 1). Currently, ocelot distribution within the USA is limited to the southern tip of Texas (Tewes \& Everett, 1986; Fig. 1), where there are only two known breeding populations; one in and around Laguna Atascosa National Wildlife Refuge in eastern Cameron County and the other on Yturria Ranch, a private ranch in Willacy County (Navarro-Lopez, 1985; Laack, 1991; Fig. 2). Individual ocelots have been reported elsewhere but there is no evidence of other breeding populations occurring in the USA. Consequently the ocelot population in the USA was listed as Endangered by the US Fish and Wildlife Service in 1982, and in 1989 was included on Appendix 1 of CITES. In addition, Leopardus pardalis albescens is categorized as Endangered on the IUCN Red List (IUCN, 2004).

Identification and monitoring of ocelots in the USA will facilitate assessment of population status, monitoring of population variability, and identification of factors that promote population expansion or contraction. However, ocelots are secretive, solitary, nocturnal, and prefer dense thornscrub, which makes them difficult to study.

\footnotetext{
Aaron M. Haines (Corresponding author), Jan E. Janecka,

Michael E. Tewes, Lon I. Grassman Jr and Patricia Morton Feline Research Program, Caesar Kleberg Wildlife Research Institute, 700 University Blvd., MSC 218, Texas A\&M University-Kingsville, Kingsville, TX 78363, USA. E-mail ksamh03@tamuk.edu
}

Received 5 October 2004. Revision requested 26 January 2005. Accepted 27 April 2005
However, the use of camera traps has been successful in monitoring and analyzing capture-recapture data for felids such as tiger Panthera tigris (Karanth \& Nichols, 1998), leopard Panthera pardus (Henschel \& Ray, 2003), bobcat Lynx rufus (Heilbrun et al., 2003), jaguar Panthera onca (Silver et al., 2004) and ocelot (Trolle \& Kéry, 2003). The objectives of this study were to (1) identify ocelot presence in southern Texas outside Laguna Atascosa National Wildlife Refuge, and (2) estimate ocelot population size and density within these areas.

\section{Study sites}

Our survey sites consisted of two private ranches (Yturria and Corbett Ranches) and two nature sanctuaries (Nature Conservancy Southmost Nature Preserve and Sabal Palm Audubon Wildlife Sanctuary) located within the Lower Rio Grande Valley of Texas in Willacy and Cameron Counties (Fig. 2). The Yturria Ranch contains two connected conservation easements $\left(3.8 \mathrm{~km}^{2}\right)$ owned by the US Fish and Wildlife Service, on which we conducted our survey. A conservation easement is a legal agreement placed by a landowner that restricts certain future uses of a piece of property to ensure that it will be managed to preserve natural features. The $37.3 \mathrm{~km}^{2}$ Corbett Ranch lies to the west. The two nature sanctuaries (Southmost, $3.8 \mathrm{~km}^{2}$; Sabal, $3 \mathrm{~km}^{2}$ ) are located along the Rio Grande River, $2.5 \mathrm{~km}$ apart (Fig. 2).

The Lower Rio Grande Valley is an alluvial plain dissected by numerous natural drainages that flow into the Rio Grande River or the Gulf of Mexico (Everitt \& Drawe, 1993). The subtropical, semi-arid climate is characterized by hot summers and mild winters (Thornthwaite, 1948; Lonard \& Judd, 1985). Mean length of the frost-free 


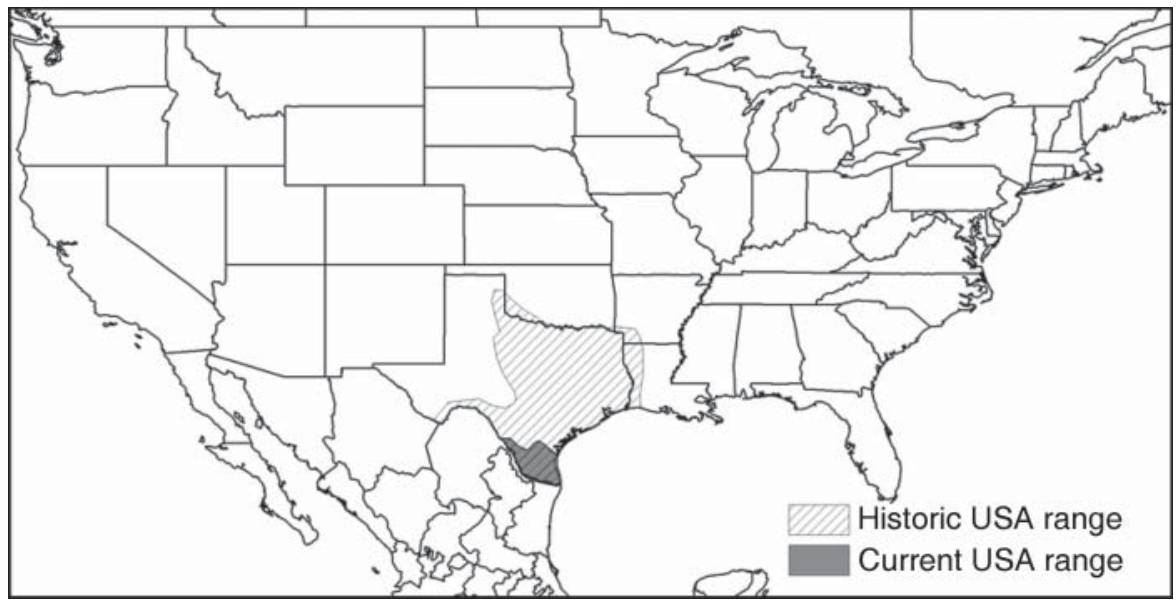

Fig. 1 Historic and current range of ocelot within the United States.

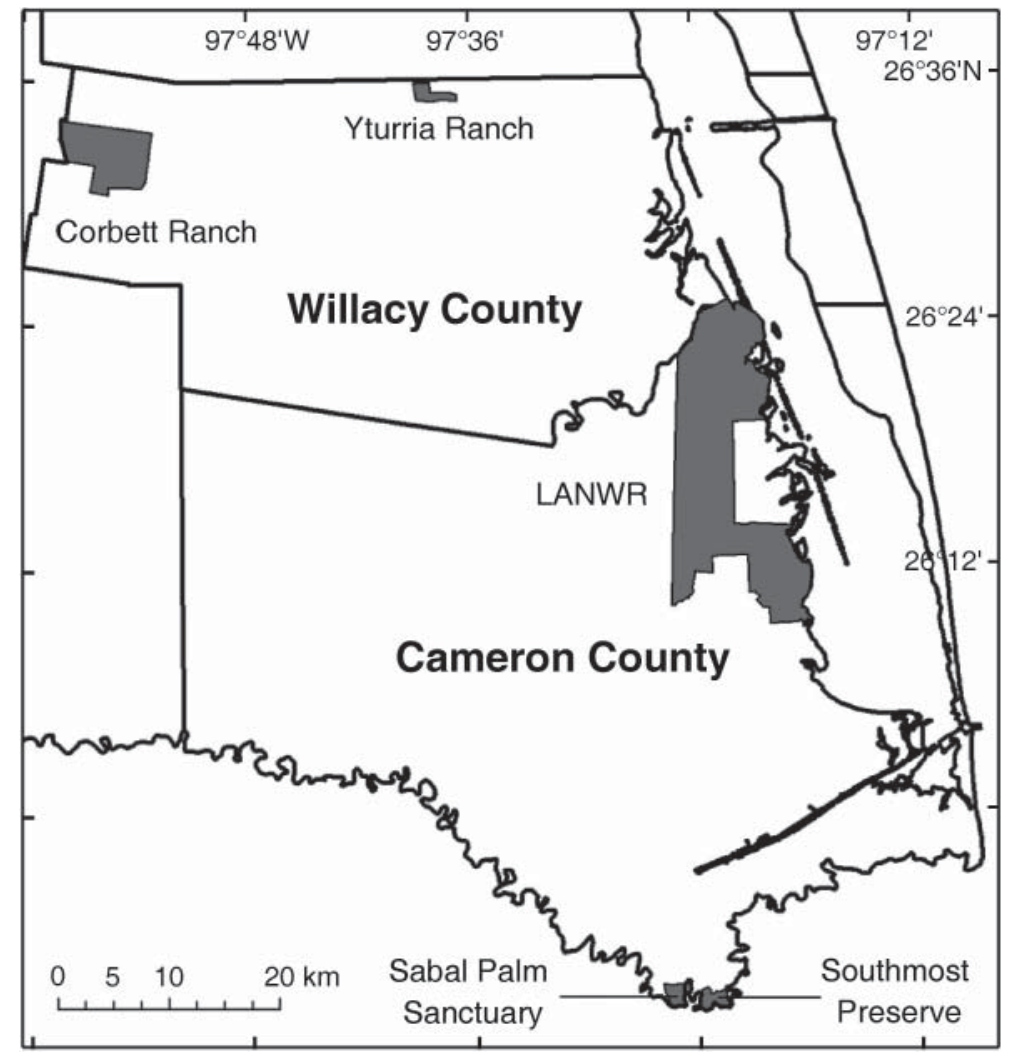

Fig. 2 Location of Laguna Atascosa National Wildlife Refuge (LANWR) and the four study sites within the Lower Rio Grande Valley of southern Texas in Willacy and Cameron Counties. period is 330 days with winters frequently being above freezing temperatures. Mean annual temperature and rainfall are $23^{\circ} \mathrm{C}$ and $68 \mathrm{~cm}$, although rainfall fluctuates widely through the year (Norwine \& Bingham, 1985; Lonard et al., 1991).

\section{Methods}

We used camera traps during three separate survey periods: 2 October-18 December 2003 on the Yturria and Corbett Ranches, 15 February-15 April 2004 on the Corbett Ranch, and 1 July-1 September 2004 on the Southmost and Sabal Preserves. Ocelot activity has been found to be consistent year-round (Tewes, 1986; Laack, 1991; Laack et al., 2004), and therefore we assumed that time of year did not affect camera trapping success.

We set up camera traps (three Trailmaster activeinfrared units, model TM1550, Goodson and Associates, Inc., Lenexa, USA, and five CamTrakker passive-infrared units, model 'Big Buck Surveillance System', Camtrack 
South Inc., Watkinsville, USA) in each study area along wildlife trails. However, on the Yturria Ranch we only surveyed wildlife trails along the perimeter of the conservation easements because we were not allowed access within them. The active monitor system uses an infrared beam between a transmitter and a receiver, triggered when the beam is broken. The passive system consists of a wedge-shaped infrared field triggered by motion and heat given off by a warm-blooded animal moving through the wedge. We assumed passive and active systems produced the same capture results. Camera traps were placed such that no area greater than $2.87 \mathrm{~km}^{2}$ existed without cameras within the survey sites. The mean home range size of an adult female ocelot is $2.87 \mathrm{~km}^{2}$ (Laack, 1991), and therefore we assumed that no adult ocelots within our study areas had a zero probability of being detected.

We placed camera traps $30 \mathrm{~cm}$ above the ground. Cameras were active during $24-\mathrm{h}$ periods, with a 5 minute delay between consecutive photographs, and were checked every 2 weeks to replace film and batteries as required. We identified individual ocelots by scanning ocelot photographs to produce a digital image that could be enlarged and examined on a monitor. We examined pattern details of ocelot pelage (e.g. tail, body and facial patterns) to identify individuals (Trolle \& Kéry, 2003).

We divided each survey into 2-week periods, each of which constituted a trapping occasion. This allowed us to record the capture history of individual ocelots. We estimated population abundance using the CAPTURE software (Rexastad \& Burnham, 1991) for a closed population (Otis et al., 1978). We tested the closure assumption by using a closure test implemented in CAPTURE.

CAPTURE estimates abundance using seven models that differ in their assumptions about capture probability. Karanth \& Nichols (1998), Henschel \& Ray (2003) and Trolle \& Kéry (2003) describe these models and their assumptions. To identify the preferred model suitable for our analysis we used the model selection algorithm provided in CAPTURE, which selects a model based on a ranking criterion ranging from $0-1$, with 1 having the highest ranking. We calculated population size and standard error based on the model selected by CAPTURE.

Density estimates were calculated by dividing ocelot abundance by the sample area (Karanth \& Nichols, 1998). Sample area included a minimum convex polygon area of the camera trap locations and a buffer strip around the polygon area, of which the radius was half the mean maximum distance among multiple captures of individual ocelots during the survey periods (Wilson \& Anderson, 1985). Sample area was calculated using the Animal Movement Extension (Hooge \& Eichenlaub, 1997) of the geographical information system ArcView 3.3 (ESRI, Inc. Redlands, USA).

\section{Results}

During the first survey period (2 October-18 December 2003) we sampled 658 trap nights on the Corbett Ranch (18 trap sites, mean distance between trap sites $=2.4 \mathrm{~km}$ ), and 1,310 trap nights on the Yturria Ranch (15 trap sites, mean distance between trap sites $=1.7 \mathrm{~km}$ ). No ocelots were recorded on the Corbett Ranch. On the Yturria Ranch we recorded 20 ocelot photos from which 3 individual ocelots were identified (Plate 1) during 14 trapping occasions (28 weeks). Capture history during the 14 trapping occasions, where 1 indicates an individual was trapped during a 2-week period and 0 that it was not detected, for Male 1 was 10110000010001, Female 200000100001110 , and Female 300000110010000 . Female 2 showed signs of being pregnant (M. Sternberg, pers. obs.) providing evidence of ocelots breeding on the Yturria Ranch.

During the second survey period (15 February-15 April 2004) we sampled 224 trap nights on the Corbett Ranch but obtained no ocelot photos. During the last survey period (1 July-1 September 2004) we sampled 560 trap nights on the Southmost Preserve (10 trap sites, mean distance between trap sites $=1.1 \mathrm{~km})$, and 448 trap nights on the Sabal Preserve (8 trap sites, mean distance between trap sites $=0.8 \mathrm{~km}$ ) but obtained no ocelot photos at either site.

We estimated abundance and density of ocelots on the Yturria Ranch because this was the only study site in which ocelots were camera trapped. The closure test conducted with CAPTURE was consistent with the assumption that the ocelot population was closed $(z=-0.58$, $\mathrm{P}=0.28$ ). The model selection algorithm in CAPTURE selected the model $\mathrm{M}(\mathrm{o})$ with a model criterion of 1.0 . The $\mathrm{M}(\mathrm{o})$ model assumes that there is no variation in capture probability associated with individuals or occasions (Rexstad \& Burnham, 1991). The estimate of population size of ocelots in the conservation easements on the Yturria Ranch based on the CAPTURE model was $3 \pm$ SE 0.17 (95\% confidence interval 3-3). The variation of the estimate was minimal because of the small number of ocelots captured. The lower limit of capture probability with which a meaningful estimate of population size can be obtained is 0.1 (Otis et al., 1978), and capture probability in this study was 0.29 per occasion. The minimum convex polygon of the camera trapping area was $3.5 \mathrm{~km}^{2}$, and the total sample area that included a boundary strip of $0.65 \mathrm{~km} \pm \mathrm{SE} 0.1$ was $10.1 \mathrm{~km}^{2}$. The estimated density of ocelots in and around the conservation easements on the Yturria Ranch was therefore $0.30 \pm$ SE 0.03 ocelots km-2.

\section{Discussion}

Tewes (1986) trapped 2 ocelots on the Corbett Ranch in 1982, and the last ocelot trapped along the Rio Grande 

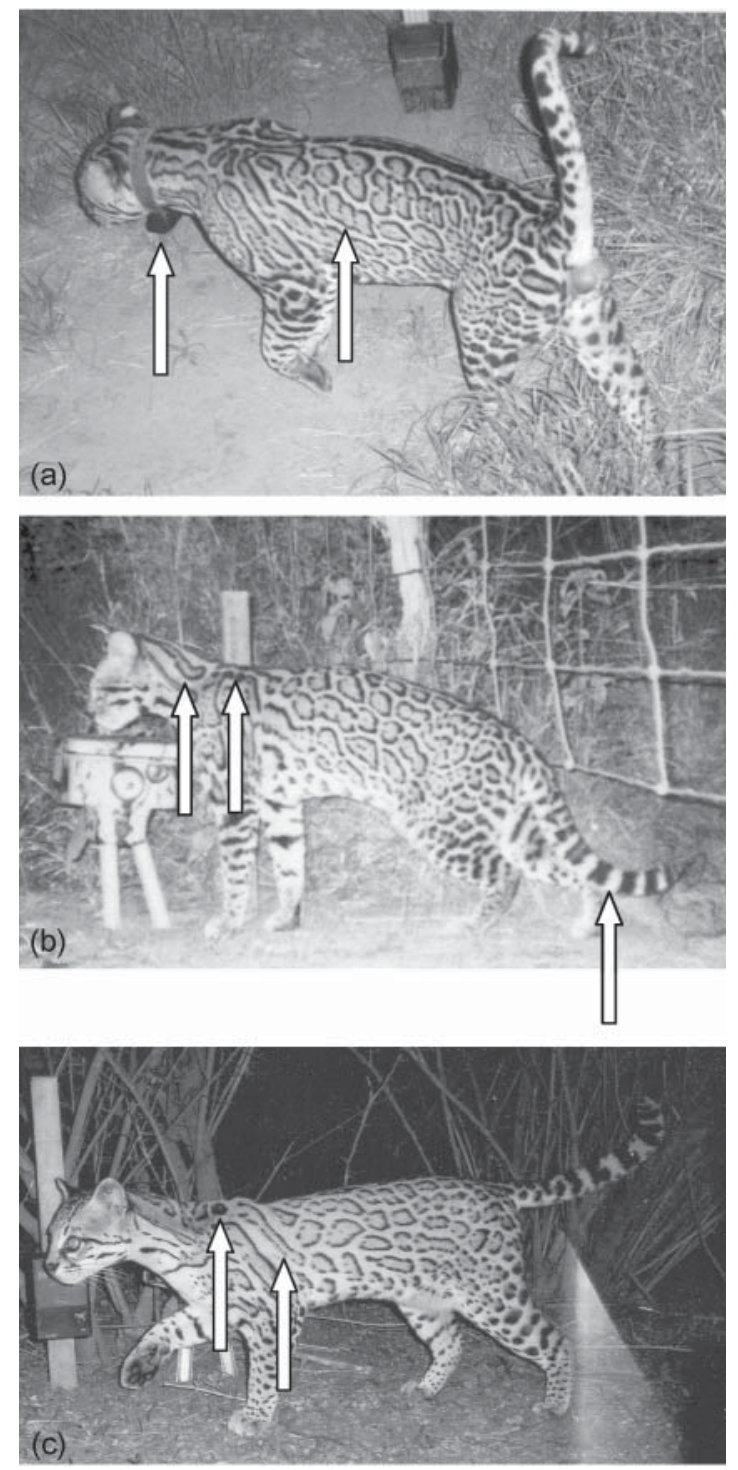

Plate 1 Camera trapping photographs of 3 ocelots: (a) male 1 fitted with radio-collar, with 3 fused rosettes on side, (b) female 2 with stocking shaped rosette along neck, two dark spots located together on top of shoulder, and tail striped with light and dark bands, and (c) female 3 with one dark spot located on top of shoulder and long rosette curved downward along side.

River was in 1995 (Fischer, 1998). However, our study produced no evidence of ocelot presence in either of these locations. We only recorded ocelot presence on conservation easements on the Yturria Ranch. It is possible that transient and dispersing ocelots may occasionally occur on the Corbett Ranch or along the Rio Grande River, but there is no evidence of the existence of a breeding population at either site.

The estimate of ocelot density reported in this study $\left(0.30\right.$ ocelots $\left.\mathrm{km}^{-2}\right)$ is within the range of density estimates reported elsewhere for ocelots: 0.40 ocelots $\mathrm{km}^{-2}$ in Venezuela (Ludlow \& Sunquist, 1987), 0.80 ocelots $\mathrm{km}^{-2}$ in the Peruvian rainforest (Emmons, 1988), 0.18 ocelots $\mathrm{km}^{-2}$ in Iguaza National Park, Brazil (Crawshaw, 1995), and 0.08 male and 0.17 female ocelots $\mathrm{km}^{-2}$ in Jalisco, Mexico (Fernandez, 2002). All of these estimates were based on telemetry data and available habitat. Trolle \& Kéry (2003) used camera trapping data to calculate a density estimate of 0.56 ocelots $\mathrm{km}^{-2}$ in the Pantanal of Brazil. López González et al. (2003) calculated a density estimate of 0.06 ocelots $\mathrm{km}^{-2}$ in Sonora, Mexico, using records of ocelot observations within the region extrapolated to the amount of habitat associated with the ocelot records. The extrapolation, however, makes this density estimate questionable.

It is important to note that our estimate of ocelot density is based on only one site, and access to the conservation easements on the Yturria Ranch was limited. Density may thus be underestimated. This study should be followed by further surveys in southern Texas and on the Yturria Ranch.

The Lower Rio Grande Valley in southern Texas has the most impoverished and rapidly growing border population of humans in the USA (Fulbright \& Bryant, 2002). This growth is increasing the rate of habitat fragmentation and threatening the preservation of ocelot habitat, further emphasizing the importance of continued camera trap monitoring of ocelot populations in this region.

Yturria Ranch contains only the second known breeding population of ocelots in southern Texas, and thus conservation strategies should be implemented in and around the ranch area. More importantly, because 97\% of Texas is privately owned and most ocelots reside on private land (Carroll, 1994; Tewes, 2001), ocelot conservation has to rely heavily on the support of private ranchers (Carroll, 1994; Tewes, 2001; Conover, 2002). To encourage habitat conservation and restoration, and possible establishment of corridors, private ranchers should continue to receive adequate support from the federal government with conservation easements and incentives (Carroll, 1994; Conover, 2002).

\section{Acknowledgements}

We thank J. Paz and M. Pons for allowing access and providing invaluable support during this study, M. Corbett and F. Yturria for allowing us access to their property, and M. Sternberg for his council. Earlier drafts of this manuscript were reviewed by L. Brennan and an anonymous reviewer. This project was supported by funds from the US Fish and Wildlife Service Project and Tim and Karen Hixon. This is Caesar Kleberg Wildlife Research Institute manuscript \#05-102. 


\section{References}

Carroll, G. (1994) Cat on the spot. National Wildlife, 32, 34-37.

Conover, A. (2002) Not a lot of ocelots. Smithsonian Magazine, June, 64-68.

Crawshaw, P.G. (1995) Comparative ecology of ocelot (Felis pardalis) and jaguar (Panthera onca) in a protected subtropical forest in Brazil and Argentina. PhD thesis, University of Florida, Gainsville, USA.

Emmons, L.H. (1988) A field study of ocelots (Felis pardalis) in Peru. Revue d'Ecologie (la Terre et la Vie), 43, 133-157.

Everitt, J.H. \& Drawe, D.L. (1993) Trees, Shrubs, and Cacti of South Texas. Texas Tech University Press, Lubbock, USA

Fernandez, E. (2002) Effects of fragmentation on the ocelot (Leopardus pardalis) in a tropical decidous forest of Mexico. MSc thesis, University of Wyoming, Laramie, USA.

Fischer, C.V. (1998) Habitat use by free-ranging felids in an agroecosystem. MSc thesis, Texas A\&M University, Kingsville, USA.

Fulbright, T.E. \& Bryant, F.C. (2002) The Last Great Habitat. Special Publication Number 1. Caesar Kleberg Wildlife Research Institute, Kingsville, USA

Heilbrun, R.D., Silvy, N.J., Tewes, M.E. \& Peterson, M.J. (2003) Using automatically triggered cameras to individually identify bobcats. Wildlife Society Bulletin, 31, 748-755.

Henschel P. \& Ray, J.C. ( 2003) Leopards in African Rainforests: Survey and Monitoring Techniques. Wildlife Conservation Society Global Carnivore Program Http:/ / www.savingwildplaces.com/media/file/low-leopard.pdf [accessed 19 August 2005].

Hooge, P.N. \& Eichenlaub, B. (1997) Animal Movement Extension to ArcView Version 1.1 and Later. Alaska Biological Science Center, US Geological Survey, Anchorage, USA.

IUCN (2004) 2004 IUCN Red List of Threatened Species. IUCN, Gland, Switzerland [http:/ / www.redlist.org, accessed 17 August 2005].

Karanth, K.U. \& Nichols, J.D. (1998) Estimation of tiger densities in India using photographic captures and recaptures. Ecology, 79, 2852-2862.

Laack, L.L. (1991) Ecology of the ocelot (Felis pardalis) in south Texas. MSc thesis, Texas A\&M University, Kingsville, USA.

Laack, L.L., Tewes, M.E., Haines, A.H. \& Rappole, J.H. (2004) Reproductive ecology of ocelot (Leopardus pardalis) in southern Texas. In Current Research of the Caesar Kleberg Wildife Institute 2004-2005 (ed. A.M. Fedynich), pp. 61-62. Texas A\&M University, Kingsville, Texas.

Lonard, R.I., Everitt, J.H. \& Judd, F.W. (1991) Woody plants of the lower Rio Grande Valley, Texas. Texas Journal of Science, 45, 133-147.

Lonard, R.I. \& Judd, F.W. (1985) Effects of a severe freeze on native woody plants in the Lower Rio Grande Valley, Texas. Southwestern Naturalist, 30, 397-403.

López González, C.A., Brown, D.E., \& Gallo Reynoso, J.P. (2003) The ocelot Leopardus pardalis in north-western Mexico: ecology, distribution and conservation status. Oryx, 37, 358-363.

Ludlow, M.E. \& Sunquist, M.E. (1987) Ecology and behavior of ocelots in Venezuela. National Geographic Research, 3, 447-461.

Navarro-Lopez, D. (1985) Status and distribution of the ocelot (Felis pardalis) in south Texas. MSc thesis, Texas A\&M University, Kingsville, USA.

Norwine, J. \& Bingham, R. (1985) Frequency and severity of drought in south Texas. In Livestock and Wildlife Management During Drought (ed. R. Brown), pp. 1-19. Caesar Kleberg Wildlife Research Institute Press, Kingsville, USA.
Otis, D.L., Burnham, K.P., White, G.C. \& Anderson, D.R. (1978) Statistical inference from capture data on closed animal populations. Wildlife Monographs, 62, 1-135.

Rexstad, E. \& Burnham, K.P. (1991) User's Guide for Interactive Program CAPTURE: Abundance Estimation of Closed Animal Populations. Colorado State University, Fort Collins, USA.

Silver, S.C., Ostro, L.E.T., Marsh, L.K., Maffei, L., Noss, A.J., Kelly, M.J., Wallace, R.B., Gomez, H. \& Ayala, G. (2004) The use of camera traps for estimating jaguar Panthera onca abundance and density using capture/recapture analysis. Oryx , 38, 148-154.

Tewes, M.E. (1986) Ecological and behavioral correlates of ocelot spatial patterns. PhD thesis, University of Idaho, Moscow, USA

Tewes, M.E. (2001) Ghost cat of south Texas. Texas Parks $\mathcal{E}$ Wildife, September, 20-25.

Tewes, M.E. \& Everett, D.D. (1986) Status and distribution of the endangered ocelot and jaguarundi in Texas. In Cats of the World: Biology, Conservation, and Management (eds S.D. Miller \& D.D. Everett), pp. 147-158. Caesar Kleberg Wildlife Research Institute Press, Kingsville, Texas, USA, and National Wildlife Federation, Washington, DC, USA.

Thornthwaite, C.W. (1948) An approach toward a rational classification of climate. Geographical Review, 38, 55-94.

Trolle, M. \& Kéry, M. (2003) Estimation of ocelot density in the Pantanal using capture-recapture analysis of camera-trapping data. Journal of Mammology, 84, 607-614.

US Fish and Wildlife Service (1982) Endangered and threatened wildlife and plants; endangered status for US population of the ocelot. Federal Registar, 47, 31670-31672.

Wilson, K.R. \& Anderson, D.R. (1985) Evaluation of two density estimators of small mammal population size. Journal of Mammalogy, 66, 13-21.

Woodward, D.W. (1980) The Ocelot. Selected vertebrate endangered species of the sea coast of the United States. FWS/OBS/01.9. Washington, DC, USA.

\section{Biographical sketches}

Aaron M. Haines's research interests include ocelot recovery and conservation, ecology of wild felids, bobwhite quail management and raptor ecology.

Jan E. Janecka's research interests include research on the ecology, conservation, and population genetics of felids, and on combining genetic and biological data to estimate important population parameters and to gain insight into the ecology of felids.

Michael E. Tewes is coordinator of the Feline Research Program at the Caesar Kleberg Wildlife Research Institute. With his graduate students he has been studying wild cats for over 20 years. This research has covered several carnivore species in the USA, Mexico, Thailand and Taiwan.

Lon I. Grassman Jr has worked extensively in Thailand, studying carnivore ecology for over 8 years. He is particularly interested in wild cat conservation issues.

Patricia Morton works for Texas Parks and Wildlife, and her research interests include bat ecology and conservation, and environmental education. 